\title{
Serrated polyposis associated with a family history of colorectal cancer and/or polyps: The preferential location of polyps in the colon and rectum defines two molecular entities
}

\author{
PATRÍCIA SILVA $^{1 *}$, CRISTINA ALBUQUERQUE ${ }^{1 *}$, PEDRO LAGE $^{2,3}$, VANESSA FONTES $^{1}$, RICARDO FONSECA $^{4}$, \\ INÊS VITORIANO ${ }^{1}$, BRUNO FILIPE ${ }^{1}$, PAULA RODRIGUES ${ }^{3}$, SUSANA MOITA ${ }^{1}$, SARA FERREIRA ${ }^{2,3}$, \\ RITA SOUSA $^{2,5}$, ISABEL CLARO ${ }^{2,3}$, CARLOS NOBRE LEITÃO ${ }^{2,6}$, \\ PAULA CHAVES $^{4}$ and ANTÓNIO DIAS PEREIRA ${ }^{2}$ \\ ${ }^{1}$ Molecular Pathobiology Research Unit (UIPM), ${ }^{2}$ Gastroenterology Service, ${ }^{3}$ Familial Cancer Risk Clinic, \\ ${ }^{4}$ Pathology Service, Portuguese Institute of Oncology of Lisbon Francisco Gentil, E.P.E. (IPOLFG, EPE), Lisbon, Portugal
}

Received November 13, 2015; Accepted March 11, 2016

DOI: $10.3892 / \mathrm{ijmm} .2016 .2666$

\begin{abstract}
Serrated polyposis (SPP) is characterized by the development of multiple serrated polyps and an increased predisposition to colorectal cancer (CRC). In the present study,

Correspondence to: Dr Cristina Albuquerque, Molecular Pathobiology Research Unit (UIPM), Portuguese Institute of Oncology of Lisbon Francisco Gentil, E.P.E. (IPOLFG, EPE), Rua Professor Lima Basto, 1099-023 Lisbon, Portugal

E-mail: mc.albuquerque@sapo.pt
\end{abstract}

Present addresses: ${ }^{5}$ Garcia de Orta Hospital, E.P.E., Almada, Portugal; ${ }^{6}$ Lusíadas Lisbon Hospital, Lisbon, Portugal

${ }^{*}$ Contributed equally

Abbreviations: AD, adenomatous; $A P C$, adenomatous polyposis coli; $\mathrm{AD} / \mathrm{S}$, adenomatous/serrated; $B R A F, \mathrm{~B}$-raf proto-oncogene, serine/threonine kinase; $\mathrm{Ca}$, carcinoma; CIMP, $\mathrm{CpG}$ island methylator phenotype; CRC, colorectal cancer; CTNNB1, catenin beta 1; KRAS, Kirsten rat sarcoma viral oncogene homolog; HCM, hyperplastic colonic mucosa; HP, hyperplastic polyp; LOH, loss of heterozygosity; MDE, mutation detection enhancement; $M G M T$, O-6-methylguanine-DNA methyltransferase; $M L H 1$, mutL homolog 1; MMR, mismatch repair; MSI, microsatellite instability; MSI-H, microsatellite instability-high; MSI-L, microsatellite instability-low; MSS, microsatellite stable; MSH3, mutS homolog 3; MSH6, mutS homolog 6; NCM, normal colonic mucosa; NRAS, neuroblastoma RAS viral (v-ras) oncogene homolog; PCR, polymerase chain reaction; PTT, protein truncation test; SCa, serrated carcinoma; SE, serrated; SPP, serrated polyposis; SPP-FHP/CRC, SPP associated with a family history of SPP and/or polyps/CRC (multiple or diagnosed at a young age) in first-degree relatives; SSA, sessile serrated adenoma; SSCP, single-strand conformational polymorphism; TA, tubular adenoma; TSA, traditional serrated adenoma; TVA, tubulovillous adenoma

Key words: colorectal cancer, genotoxic susceptibility, O-6-methylguanine-DNA methyltransferase, mismatch repair gene methylation, serrated polyposis, proximal vs. distal colon we aimed to characterize, at a clinical and molecular level, a cohort of SPP patients with or without a family history of SPP and/or polyps/CRC (SPP-FHP/CRC). Sixty-two lesions from 12 patients with SPP-FHP/CRC and 6 patients with sporadic SPP were included. The patients with SPP-FHP/CRC presented with an older mean age at diagnosis $(p=0.027)$ and a more heterogeneous histological pattern of lesions $(p=0.032)$ than the patients with sporadic SPP. We identified two molecular forms of SPP-FHP/CRC, according to the preferential location of the lesions: proximal/whole-colon or distal colon. Mismatch repair (MMR) gene methylation [mutS homolog 6 (MSH6)/mutS homolog 3 (MSH3)] or loss of heterozygosity (LOH) of D2S123 (flanking MSH6) were detected exclusively in the former $\left(\mathrm{p}=3.0 \times 10^{-7}\right)$, in most early lesions. Proximal/whole-colon SPP-FHP/CRC presented a higher frequency of O-6-methylguanine-DNA methyltransferase (MGMT) methylation/LOH, microsatellite instability (MSI) and Wnt mutations (19/29 vs. 7/17; $16 / 23$ vs. $1 / 14, \mathrm{p}=2.2 \times 10^{-4} ; 15 / 26$ vs. $2 / 15, \mathrm{p}=0.006$; $14 / 26$ vs. $4 / 20, p=0.02$ ) but a lower frequency of $B-r a f$ proto-oncogene, serine/threonine kinase $(B R A F)$ mutations ( $7 / 30$ vs. $12 / 20, p=0.0089)$ than the distal form. CRC was more frequent in cases of Kirsten rat sarcoma viral oncogene homolog (KRAS)-associated proximal/whole-colon SPP-FHP/ $\mathrm{CRC}$ than in the remaining cases $(4 / 4$ vs. $1 / 8, \mathrm{p}=0.01)$. Thus, SPP-FHP/CRC appears to be a specific entity, presenting two forms, proximal/whole-colon and distal, which differ in the underlying tumor initiation pathways. Early MGMT and MMR gene deficiency in the former may underlie an inherited susceptibility to genotoxic stress.

\section{Introduction}

Serrated polyposis (SPP), which was previously known as hyperplastic polyposis, is characterized by the presence of multiple colorectal epithelial polyps with a serrated architecture, termed serrated (SE) polyps, as well as an increased predisposition to colorectal cancer (CRC) (1-3). SE polyps differ from adenomatous (AD) polyps and are comprised of various lesions, 
namely: hyperplastic polyps (HPs), non-dysplastic lesions with normal proliferation and architecture but elongated crypts with a saw-toothed appearance; sessile serrated adenomas (SSAs), lesions that present abnormal proliferation and architecture and may or may not include dysplasia; and traditional serrated adenomas (TSAs) that are dysplastic polyps with prominent serration (1,4-6). The presence of multiple SE polyps has also been associated with other hereditary conditions, namely serrated pathway syndrome or Jass syndrome (7-9).

It has been proposed that these SE lesions arise through the serrated pathway rather than through the adenoma-carcinoma sequence pathway (7,10-13). It has also been suggested that the HP is the precursor lesion in this pathway, with SSA as an intermediate step which then progresses to an adenocarcinoma with or without microsatellite instability (MSI or MSS, respectively). At the molecular level, SE lesions associated with those hereditary serrated syndromes share some genetic alterations, namely the presence of B-raf proto-oncogene, serine/threonine kinase $(B R A F)$ mutations and the methylator phenotype, termed $\mathrm{CpG}$ island methylator phenotype (CIMP) (14-16), although these are also common to the sporadic SE lesions.

However, the analysis of SPP lesions has revealed specific features which are distinct from the SE lesions occurring in a sporadic context; accordingly, in SPP, HPs, TSAs and CRC are preferentially located in the proximal colon, i.e. proximal to the splenic flexure (17-19). Moreover, patients with SPP have previously been found to present extensive DNA methylation in the normal mucosa of the proximal colon (20), suggesting the involvement of widespread gene promoter methylation (CIMP) $(7,14,21)$. This phenotype appears to be related to MutL homolog $1(M L H 1)$ methylation, which has been associated with MSI status, rather than O-6-methylguanine-DNA methyltransferase (MGMT) methylation. However, MSI appears to be less frequent in SPP lesions than in sporadic lesions $(14,22)$. Similarly, SPP lesions also exhibited a lower frequency of Kirsten rat sarcoma viral oncogene homolog (KRAS) mutations when compared with sporadic SE lesions $(21,22)$. However, it was also found that most adenomas and CRCs from patients with SPP exhibited a classic morphology and that few of these had $B R A F$ or KRAS mutations, although SE lesions presented a high frequency of mutations in these genes (22). Previous research has suggested that tumorigenesis associated with SPP may not necessarily follow the serrated pathway and may follow an alternate pathway, involving TSAs and tubulovillous adenomas (TVAs) as intermediate lesions that progress to MSS adenocarcinomas with KRAS mutations or even a traditional pathway with adenomatous polyposis coli $(A P C)$ mutations as the initiating events (10).

A review of published case studies of SPP reported that approximately $10-50 \%$ of patients with SPP have been described as having a family history of CRC (23). In agreement with these findings, several studies have described an increased risk of CRC in the first-degree relatives of probands diagnosed with SPP compared with the general population $(2,17,18,24-28)$. These studies have contributed to the notion that there are SPP cases where heredity may play a role in the development of CRC and/or polyps. Indeed, another review on this subject reinforces the concept that familial SPP exists and also the importance of defining the genetic basis of familial SPP and of studying these families in a systematic manner (29).
Thus, in the present study, we aimed to characterize, at the clinical and molecular level, SE and AD lesions from a cohort of patients with SPP who had been stratified into two groups: patients with or without a family history of SPP and/or polyps/CRC in first-degree relatives, in order to elucidate the information available regarding this new SPP entity with an apparent hereditary component.

\section{Patients and methods}

Patients and specimens. Eighteen patients diagnosed with SPP according to the WHO diagnostic criteria (1) were included in this study: 12 patients with SPP associated with a family history of SPP and/or polyps/CRC (multiple or diagnosed at a young age) in first-degree relatives (designated herein as SPP-FHP/CRC) (11 index and one affected relative diagnosed simultaneously with the index patient), and 6 index patients without a family history of SPP/polyps/CRC (designated herein as sporadic SPP) from the familial colorectal cancer registry of the Portuguese Institute of Oncology of Lisbon Francisco Gentil (Lisbon, Portugal). No evidence of SPP and/or polyps/CRC was found in the first-degree relatives of the patients with sporadic SPP, either by regular colonoscopy examination or by the absence of symptoms. The patients were classified as presenting a family history of polyps in first-degree relatives $(5 / 11)$, if at least one relative had been diagnosed with polyps at or under 52 years of age or with $>10$ polyps. We cannot exclude the possibility that some of these families, namely PH4 or PH6, may have Jass syndrome instead of SPP, due to the presence of a mixture of AD and SE lesions $(7,9)$. All patients had developed $>10$ lesions prior to the date of recruitment.

Sixty-two lesions were included here: 1 hyperplastic colonic mucosa (HCM), 25 HPs, 8 TSAs, 11 SSAs, 1 adenomatous/serrated (AD/S) carcinoma $(\mathrm{Ca}), 1$ serrated carcinoma (SCa), 8 tubular adenomas (TAs), 2 TVAs and $5 \mathrm{Ca}$. Two normal colonic mucosa (NCM) samples were also included in this study. Fresh colorectal lesions were obtained from colectomy or colonoscopy specimens from patients who underwent surgery or colonoscopy in the Portuguese Institute of Oncology of Lisbon Francisco Gentil. Sections from corresponding areas of the specimens submitted for diagnosis were divided into two parts: one was snap frozen in liquid nitrogen immediately after resection, while the other was formalin-fixed and paraffin-embedded.

Histological characterization, according to the WHO guidelines (1), was performed by experienced pathologists (R.F. and P.C.). The study was conducted in accordance with local ethical standards and in agreement with the Helsinki Declaration of 1975, as revised in 1983. Informed consent for diagnosis and additional investigational studies, which may result in improving the knowledge about the pathogenesis of the disease, was obtained from patients included in this study. Moreover, biological material used for DNA isolation was obtained from archival sections from colorectal adenomas and carcinomas specimens, submitted for diagnosis (histological classification) and derived from patients who underwent surgery or colonoscopy in the Portuguese Institute of Oncology of Lisbon Francisco Gentil; only somatic analysis was performed and samples are truly anonymized. 


\section{Methods}

DNA isolation. DNA was isolated from fresh-frozen and/ or paraffin-embedded tumor tissue and matched normal tissue. DNA was isolated from the paraffin-embedded tissues by proteinase $\mathrm{K}$ digestion, which was followed by phenol/ chloroform extraction and ethanol precipitation, as previously described (30). DNA from the fresh frozen tissue was isolated by proteinase $\mathrm{K}$ digestion, followed by precipitation with a saturated $\mathrm{NaCl}$ solution and ethanol as previously described (31).

Somatic mutation analysis of the APC gene. APC mutation analysis was performed using the protein truncation test (PTT) for exon 15, as previously reported (30). Briefly, APC exon 15 was divided into four overlapping fragments that were amplified by polymerase chain reaction (PCR) and, subsequently, in vitro transcription and translation were performed using a TnT T7-coupled reticulocyte lysate system (Promega, Madison, WI, USA). In negative cases, the mutational cluster region was subsequently analyzed by automated sequencing in order to search for missense mutations. For the samples obtained from paraffin-embedded tissues, $A P C$ mutations were analyzed by single-strand conformational polymorphism (SSCP) or by automated sequencing (32).

Somatic mutation analysis of catenin beta 1 (CTNNB1). Genomic DNA from each tumor sample was amplified by PCR for SSCP analysis of exon 3 of the CTNNB1 gene. The amplified products were analyzed in a mutation detection enhancement (MDE) gel and visualized by silver staining (33).

Somatic mutation analysis of the AXIN2 gene. AXIN2 mutation analysis was performed by amplification of a repetitive sequence containing the $(\mathrm{G})_{7},(\mathrm{C})_{6}$ and $(\mathrm{C})_{5}$ tracts (where a considerable mutation frequency was described) (34), followed by electrophoresis in $7 \%$ polyacrilamide gel containing formamide and urea and visualization by silver staining (33).

Somatic mutation analysis of BRAF, KRAS and neuroblastoma RAS viral (v-ras) oncogene homolog (NRAS) genes. BRAF (exon 15: forward primer 5'-TCATAATGCTTG CTCTGATAGGA-3'; reverse primer 5'-GGCCAAAAATTT AATCAGTGGA-3', KRAS (exon 2: forward primer 5'- GTG TGACATGTTCTAATATAGTCA-3'; reverse primer 5'- GAA TGGTCCTGCACCAGTAA) (35) and NRAS (exons 2 and 3 -primers were kindly provided by Dr Branca Cavaco), were amplified by PCR. The DNA samples were amplified in a standard PCR buffer (Invitrogen, Waltham, MA, USA). Mutations in these genes were analyzed by automated sequencing.

Sequencing analysis. After amplification, PCR products were purified with Illustra GFX ${ }^{\mathrm{TM}}$ PCR DNA and Gel Band purification kit (GE Healthcare, Little Chalfont, UK) according to the manufacturer's instructions. Sequencing reactions were performed using the BigDye Terminator Cycle Sequencing kit and the respective products were analyzed on the ABI PRISM ${ }^{\mathrm{TM}} 310$ Genetic Analyzer (both from Applied Biosystems, Foster City, CA, USA) using Sequencing Analysis software. The pathogenic relevance of missense variants was evaluated by comparing aminoacid sequences using PolyPhen software (http://genetics.bwh.harvard.edu/pph/) and SIFT software (http://sift.jcvi.org/).

MSI/loss of heterozygosity ( $\mathrm{LOH}$ ) analysis. MSI status was analyzed using the Bethesda panel of reference markers (36). Each colonic lesion and paired normal DNA were amplified by PCR for each of the microsatellite markers and analyzed in the ABI Prism ${ }^{\mathrm{TM}} 310$ Genetic Analyzer using GeneScan software (Applied Biosystems). The lesions were classified as MSI-high $(\mathrm{H})$ when showing MSI in two or more of the five markers, MSI-low (L) when MSI was detected in one of the markers, and MSS when none of the markers revealed instability (37). In cases exhibiting MSI-L, BAT-40 and MYCL markers were also analyzed and the lesions were classified as MSI-H when MSI was detected in $>40 \%$ of the 7 markers analyzed; otherwise they were classified as MSI-L, as previousy described (37).

A total of 4 dinucleotide markers flanking $M G M T$ (D10S1703, D10S1676, D10S169 and D10S1651) were analyzed for each colonic lesion and paired normal DNA in order to evaluate the presence of $\mathrm{LOH}$. Each lesion was subsequently scored as demonstrating $\mathrm{LOH}$ if the ratio between the areas of the normal and the tumor alleles was $>1.5$ or $<0.67$.

Regarding the D5S346 marker, LOH was evaluated (and confirmed using the D5S1965 marker) as indicative of loss of the APC gene. LOH of D2S123 and D17S250 was also evaluated as described above.

Methylation analysis. The analysis of MGMT and mismatch repair (MMR) gene promoter methylation was performed by methylation-specific multiplex ligation-dependent probe amplification (MS-MLPA) (38) using the SALSA MS-MLPA KIT ME011 MMR, (MRC-Holland, Amsterdam, The Netherlands). MS-MLPA reactions were performed as described by the manufacturer. The samples were analyzed using GeneScan software on the ABI Prism ${ }^{\mathrm{TM}} 310$ Genetic Analyzer (Applied Biosystems). The results were normalized using MRC Coffalyser MLPA-DAT software v.9.4 (MRC-Holland). A ratio of 0.15 or higher, corresponding to $15 \%$ of methylated DNA, was indicative of promoter methylation as described elsewhere $(32,39)$.

Statistical analysis. Fisher's exact test (using a two-sided or $2 \times 3$ table) and the $\chi^{2}$ test (http://www.quantitativeskills. com/sisa/index.htm) were used to compare categorical variables, and the Student's t-test (http://www.physics.csbsju. edu/stats/t-test.html) was used to compared continuous variables. A p-value $<0.05$ was considered to indicate a statistically significant difference.

\section{Results}

Clinical characterization. Table I summarizes the clinical features of the 18 patients included in this study, stratified into two groups: SPP-FHP/CRC and sporadic SPP. The average age at diagnosis (i.e. the age at which they presented symptoms) among our cohort of SPP patients $(n=18)$ was $55 \pm 11$ years (range 25-80); however, it was significantly higher in the SPP-FHP/CRC group than in the sporadic SPP group

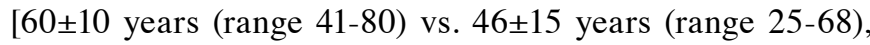
$\mathrm{p}=0.027$ (Student's t-test)] (Table II).

The number of lesions was higher in the SPP-FHP/CRC group than in the sporadic SPP group (threshold, $\geq 40$ lesions): [10/12 (83\%) vs. 3/6 (50\%) patients, respectively]. With respect to histological features, $\mathrm{AD}$ lesions were more frequent in the SPP-FHP/CRC group than in the patients with sporadic SPP [10/12 (83\%) vs. $1 / 6(17 \%), p=0.013]$. Moreover, the patients 


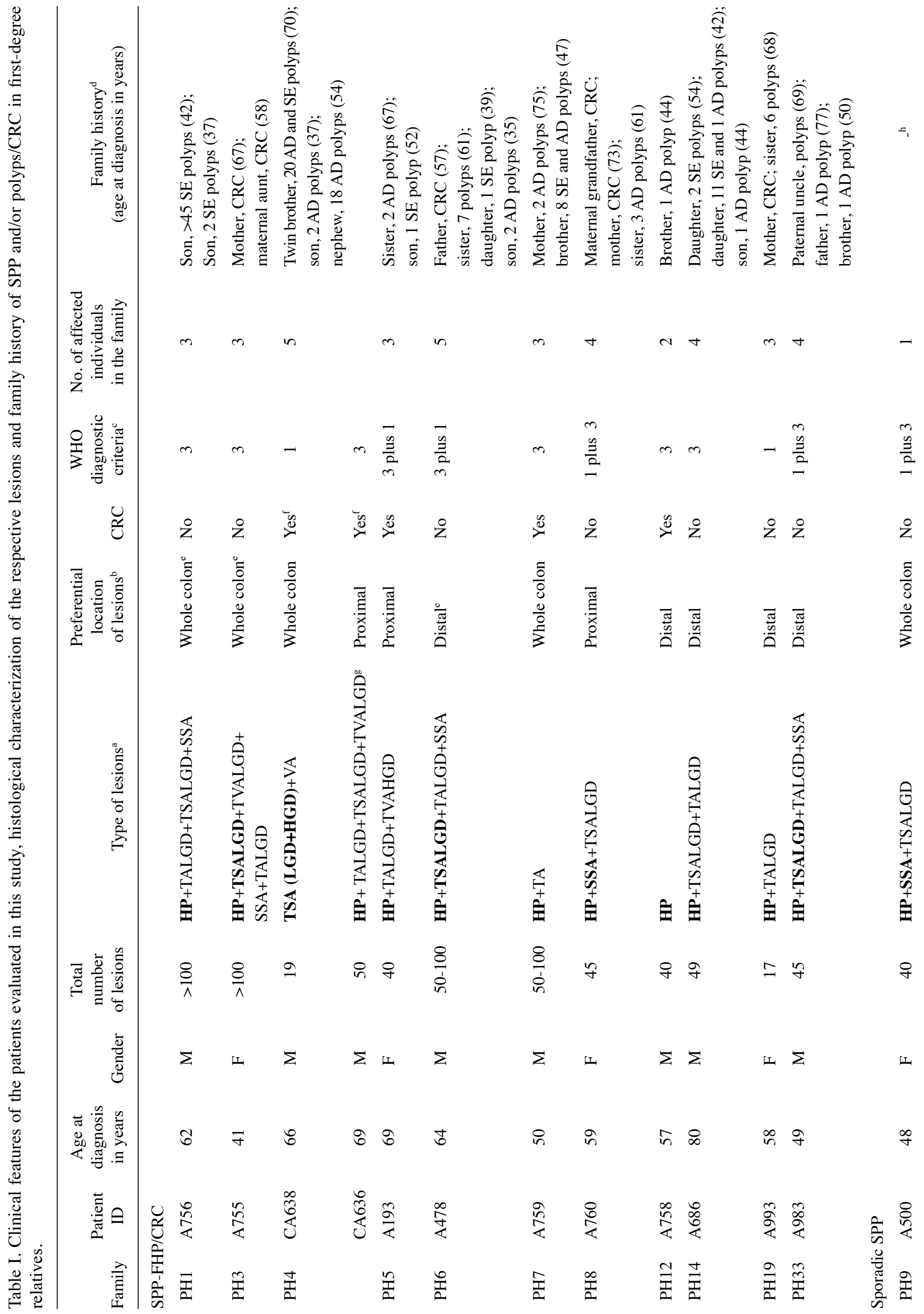




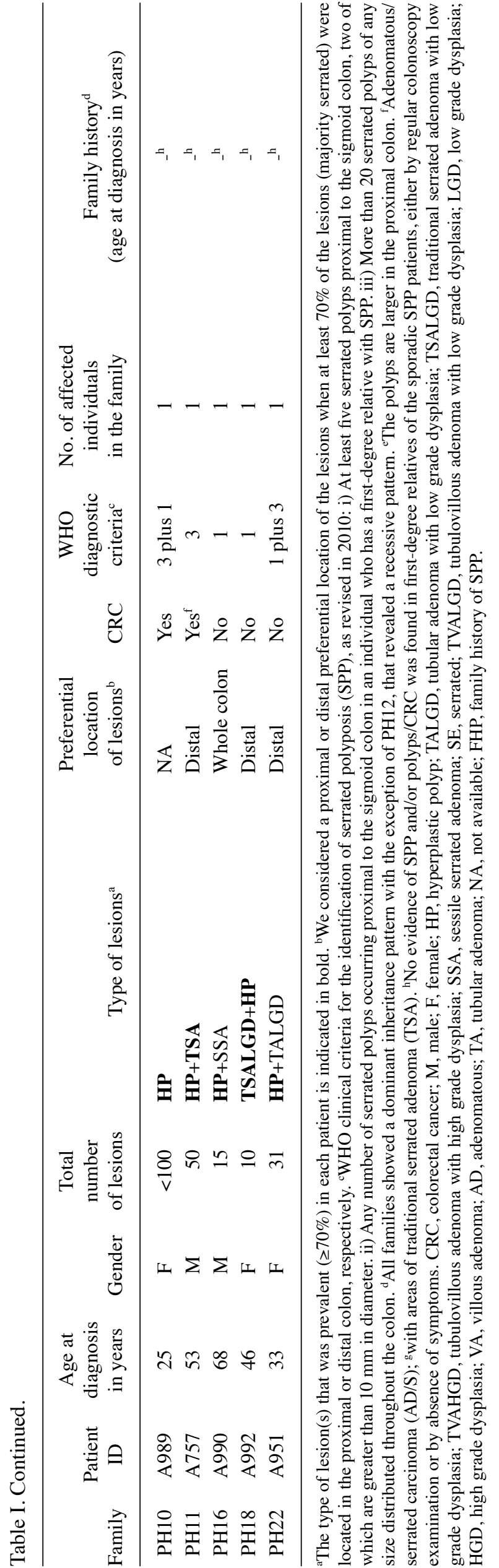

with SPP-FHP/CRC presented a more heterogeneous spectrum of lesions in comparison with the patients with sporadic SPP. In agreement with these findings, the presence of three or more types of lesions was more frequent in the former group [9/12 $(75 \%)$ vs. $1 / 6(17 \%), p=0.032]$.

Regarding the location of the lesions in each patient, we observed that whereas some of the patients with SPP presented lesions dispersed uniformly throughout the whole colon, other patients with SPP presented a predominance of lesions in one of the two major segments, proximal or distal. Therefore, a prevalence of proximal or distal location of the lesions was considered when at least $70 \%$ of the lesions (majority SE) were located in the proximal or distal colon, respectively. In accordance, a preferential proximal location was observed in $3 / 12(25 \%)$ of the SPP-FHP/CRC patients and in none of the patients with sporadic SPP (0/5). A preferential distal location was observed in $3 / 5(60 \%)$ of the sporadic SPP patients and in $5 / 12(42 \%)$ of the patients with SPP-FHP/CRC.

Molecular characterization. The molecular alterations found in each SPP-FHP/CRC lesion, namely mutations in RAS/RAF and Wnt signaling genes, MSI, MGMT and MMR methylation, LOH of MGMT locus and LOH at D2S123 and D17S250 markers, are presented in Table III. The spectra of these molecular alterations led us to observe that the somatic mutation/promoter hypermethylation spectra differs between those patients whose lesions were preferentially located in the proximal colon, or distributed throughout the whole colon, and those whose lesions were preferentially located in the distal colon, as shown in Table IV. This led us to stratify the patients with SPP-FHP/CRC into two groups, proximal/whole-colon and distal SPP-FHP/CRC.

Although the ratio between the different types of lesions in the two groups, proximal/whole-colon and distal, do not match, i.e. in the former a higher proportion of AD lesions have been analyzed [in a recent study, individuals with large and right-sided SE lesions also had significantly more AD lesions compared with those without such types of SE lesions (40)], we found differences with respect to the mutation spectrum, even considering only HPs or SSAs, which have been analyzed in both groups. Accordingly, HPs and SSAs from patients with proximal/whole-colon SPP-FHP/CRC presented RAS/RAF gene mutations less frequently [2/6 (33\%) and $1 / 7(14 \%)$ vs. $14 / 14$ and $2 / 2$, respectively, $\mathrm{p}=0.003$ and $\mathrm{p}=0.08]$ whereas MMR gene methylation or $\mathrm{LOH}$ of D2S123 [flanking mutS homolog 6 (MSH6)] occurred more frequently (4/4 and $2 / 2$ vs. $0 / 7$ and $0 / 2$, respectively, $p=0.003$ and $\mathrm{p}=0.33$ ), when compared with the same type of lesions from distal SPP-FHP/CRC patients (Table V). Moreover, SE and AD lesions presented a similar spectrum of molecular alterations, especially among each patient. The exception were $B R A F$ mutations that were significantly more frequent in SE lesions [17/36 (47\%) vs. 2/14 (14\%), p=0.05] (Table V). For each patient, either presenting proximal/whole-colon or distal SPP-FHP/CRC, the spectra of somatic molecular alterations detected in the lesions were similar regardless of the location of each specific lesion. For example, in a patient with a prevalence of proximal lesions, these presented a specific mutation pattern that was shared by the few distal lesions that were analyzed from the same patient and different from the 
Table II. Comparison between clinical features in patients with sporadic SPP and those with SPP-FHP/CRC.

\begin{tabular}{lccc}
\hline Clinical feature & SPP-FHP/CRC & Sporadic SPP & p-value \\
\hline Age at diagnosis (years) & $\mathbf{6 0 \pm 1 0}$ & $\mathbf{4 6} \pm \mathbf{1 5}$ & $\mathbf{0 . 0 2 7}$ (Student's t-test) \\
Preferential location of lesions & & & NS \\
Whole colon & $4 / 12(33 \%)$ & $2 / 5(40 \%)$ & $\mathrm{NS}$ \\
Proximal & $3 / 12(25 \%)$ & $0 / 5$ & $\mathrm{NS}$ \\
Distal & $5 / 12(42 \%)$ & $3 / 5(60 \%)$ & $\mathrm{NS}$ \\
$\geq 40$ lesions & $10 / 12(83 \%)$ & $3 / 6(50 \%)$ & $\mathbf{0 . 0 1 3}^{\mathrm{a}}$ \\
AD lesions & $\mathbf{1 0 / 1 2 ( 8 3 \% )}$ & $\mathbf{1 / 6}(\mathbf{1 7 \%})$ & $\mathbf{0 . 0 3 2}^{\mathbf{a}}$ \\
$\geq 3$ types of lesions & $\mathbf{9 / 1 2 ( 7 5 \% )}$ & $\mathbf{1 / 6}(\mathbf{1 7 \%})$ & \\
\hline
\end{tabular}

Statistically significant values are shown in bold. NS, non-significant ( $\mathrm{p}>0.05)$. ${ }^{\mathrm{a} F i s h e r ' s ~ e x a c t ~ t e s t ~(t w o-s i d e d) . ~ A D, ~ a d e n o m a t o u s ; ~ S P P, ~ s e r r a t e d ~ p o l-~}$ yposis; SPP-FHP/CRC, SPP associated with a family history of SPP and/or polyps/colorectal cancer (CRC) (multiple or diagnosed at a young age) in first-degree relatives.

proximal lesions from patients with a predominance of distal lesions and vice versa (Table IIIA).

The abovementioned findings led us to analyze the molecular data from the patients with SPP-FHP/CRC, who were stratified into two groups: proximal/whole-colon and distal SPP-FHP/CRC.

Proximal/whole-colon vs. distal SPP-FHP/CRC. Mutations in the Wnt genes, as well as MSI, were significantly more frequent in the patients with proximal/whole-colon SPP-FHP/CRC than in the patients with distal SPP-FHP/CRC [14/26 (54\%) vs. $4 / 20(20 \%), \mathrm{p}=0.02 ; 15 / 26(58 \%)$ vs. $2 / 15$ (13\%), $\mathrm{p}=0.0059$ ] (Table IV). Interestingly, among the proximal/whole-colon SPP-FHP/CRC samples, Wnt gene mutations were significantly more frequent in the SE lesions than in the AD lesions [12/16 (75\%) vs. $2 / 10(20 \%), p=0.0091]$. In the SE lesions, Wnt gene mutations, as well as MSI, were more frequent in TSAs (4/4 and 3/4) and in SSAs (6/7 and 6/7) and rarely detected in HPs $(1 / 4$ and $1 / 5)(\mathrm{p}=0.02$ and $\mathrm{p}=0.017$, respectively) (Table V).

Similarly, LOH of the MGMT locus and MGMT methylation were also more frequent in lesions from the patients with proximal/whole-colon SPP-FHP/CRC, in comparison with lesions from the patients with distal SPP-FHP/CRC [16/23 (70\%) vs. $1 / 14(7 \%), p=2.2 \times 10^{-4} ; 19 / 29(65 \%)$ vs. $7 / 17$ (41\%), $\mathrm{p}=0.1$, respectively] (Table IV). The same difference was observed even considering SE lesions only (Table V). In particular, $M G M T$ methylation was detected in all HP lesions (6/6) from proximal/whole-colon SPP-FHP/CRC, in contrast to the lower frequency observed in HPs from distal SPP-FHP/CRC $(4 / 11,36 \%)(\mathrm{p}=0.017)$.

Interestingly, among lesions which were deemed informative for methylation analysis and loss of $\mathrm{LOH}$ of D2S123, the presence of MMR gene methylation or of the D2S123 LOH (flanking MSH6) was only observed in proximal/whole-colon SPP-FHP/CRC lesions [17/18 (94\%) vs. 0/11, $\left.\mathrm{p}=3.0 \times 10^{-7}\right]$. These alterations were found in the majority of early lesions and in all histological types (Tables IIIA and IV). It is of note that $M L H 1$ methylation was not detected in any of the SPP-FHP/CRC lesions, being observed only in one lesion from the sporadic SPP group (Table IIIB). Moreover, it is also of note that except for one lesion, MSI, either MSI-L or MSI-H was detected only in dinucleotide microsatellite markers.

By contrast to the abovementioned molecular alterations, in the SPP-FHP/CRC samples, BRAF and KRAS mutations were more frequent in the lesions located in the distal colon than those located in the proximal/whole-colon $[12 / 20(60 \%)$ vs. $7 / 30(23 \%), p=0.0089\left(\chi^{2}\right.$ test $)$ and $6 / 20(30 \%)$ vs. $5 / 32(16 \%)$, respectively], although the latter was not statistically significant (Table IV). Considering only the SE lesions, mutations in the RAS/RAF genes were detected in all the lesions from the distal SPP-FHP/CRC, namely in all HPs (14/14), HCM (1/1) and in one NCM (Table IIIA), but in only 8/19 (42\%) lesions from the proximal/whole-colon SPP-FHP/CRC $\left(\mathrm{p}=1.3 \times 10^{-4}\right)$.

With respect to KRAS/BRAF mutations, two groups of patients were observed among those with either proximal/whole-colon or distal SPP-FHP/CRC: one group whose lesions presented KRAS mutations (PH4, $\mathrm{PH} 5, \mathrm{PH} 7$ and $\mathrm{PH} 14)$ and another group, whose lesions presented $B R A F$ mutations (PH3, PH8, PH19 and PH33) (Table IIIA). One patient presented either $B R A F$ - or $K R A S$-positive lesions (family PH6). Notably, CRC was more frequent in the patients with proximal/whole-colon SPP-FHP/CRC associated with KRAS mutations than in the remaining patients $[4 / 4$ vs. $1 / 8(12 \%)$, $\mathrm{p}=0.01]$ (Tables I and IIIA).

\section{Discussion}

SPP-FHP/CRC and sporadic SPP differ at the clinical level. The patients with SPP-FHP/CRC and sporadic SPP differed with respect to clinical and histological features. The older mean age at diagnosis ( 60 vs. 46 years old) of the former may underlie a slower process of tumorigenesis. This is in contrast to that which has been observed in relation to other hereditary CRC syndromes, namely in familial adenomatous polyposis and in Lynch syndrome, which are diagnosed at an earlier age (usually $\leq 50$ years old) compared to the age at diagnosis in patients with sporadic CRC $(>60$ years old) $(32,41)$. The presence of a more heterogeneous histological pattern of lesions in patients with SPP-FHP/CRC, associated with the concomitant presence of 


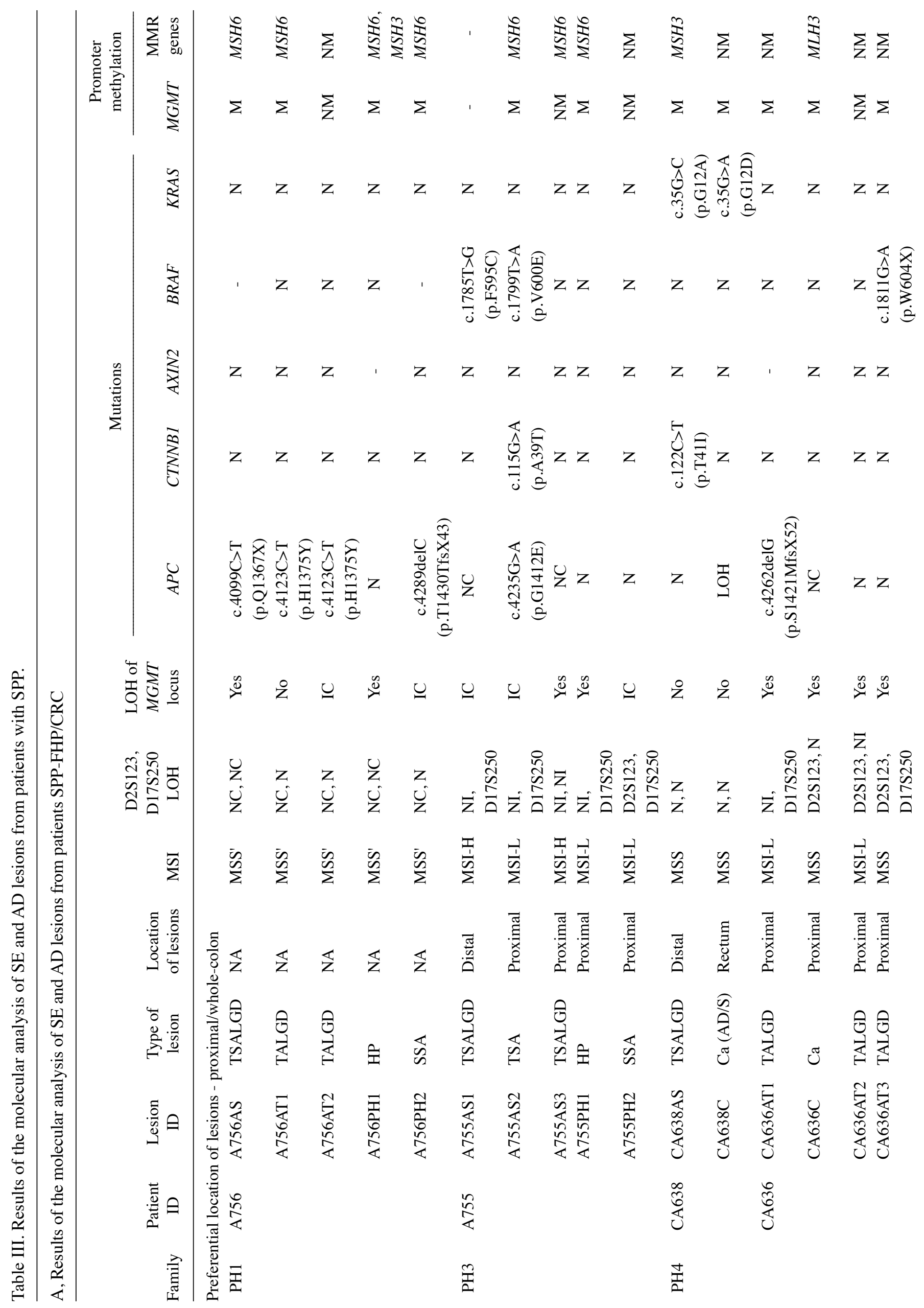




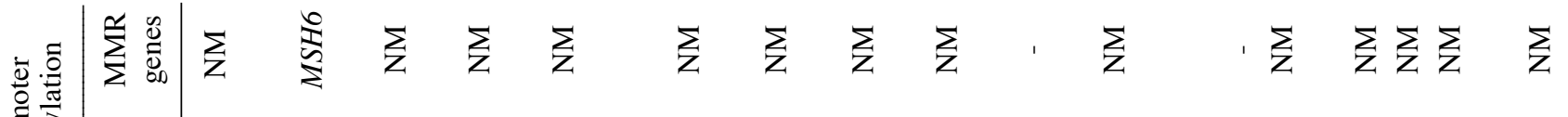
亮咅|

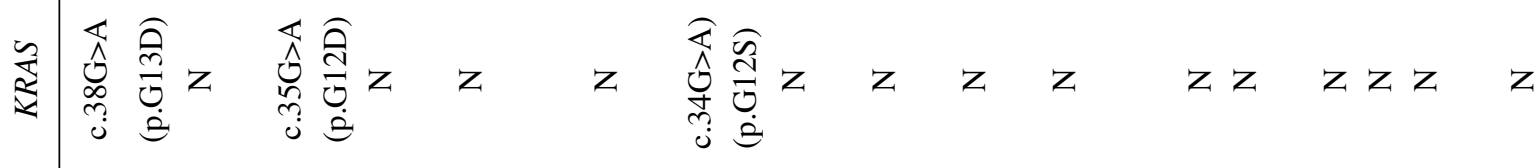

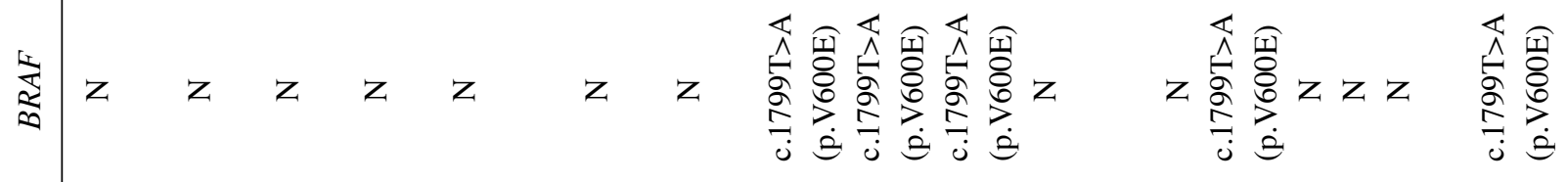

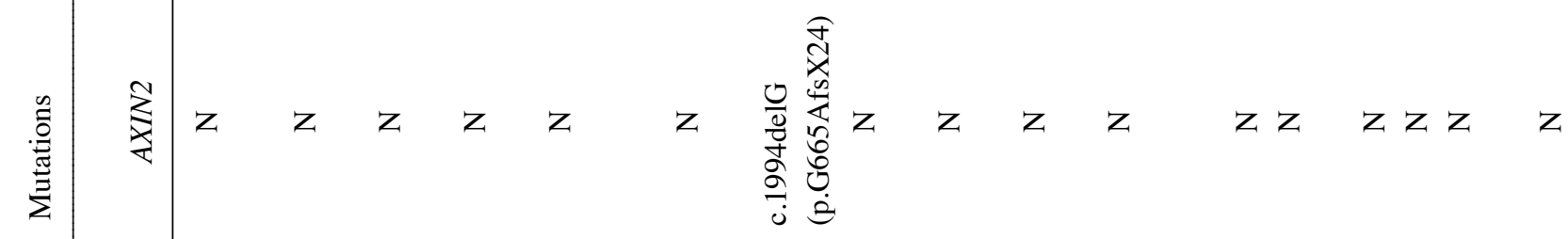

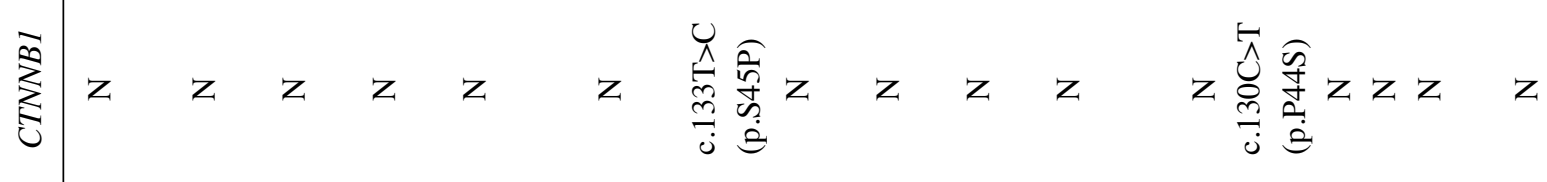

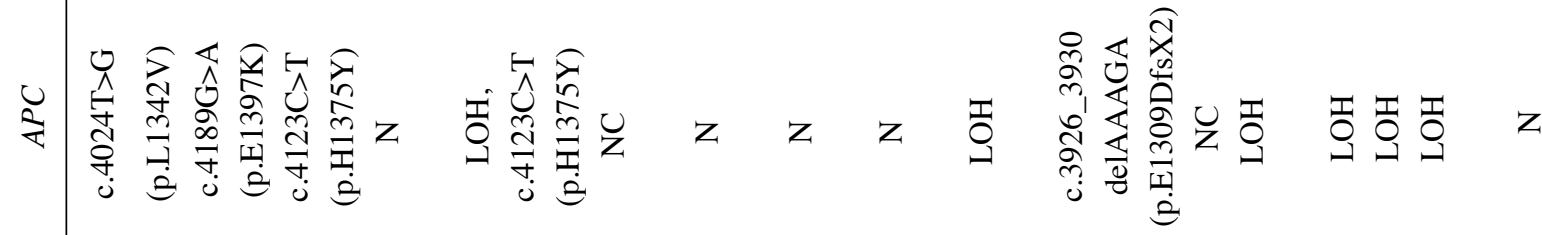

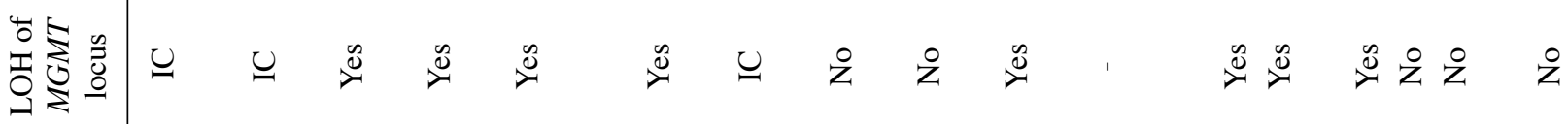

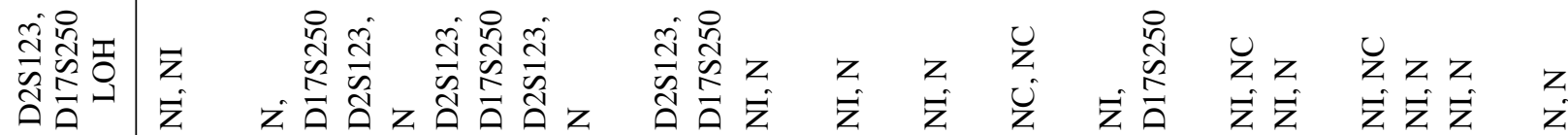

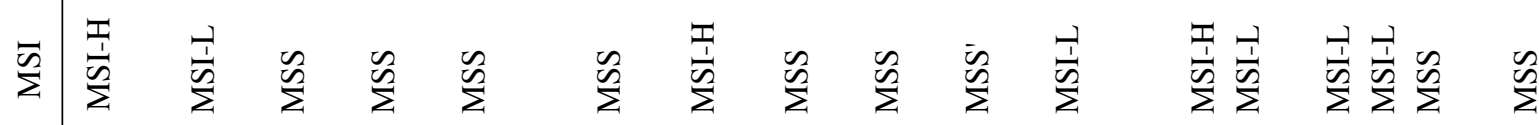



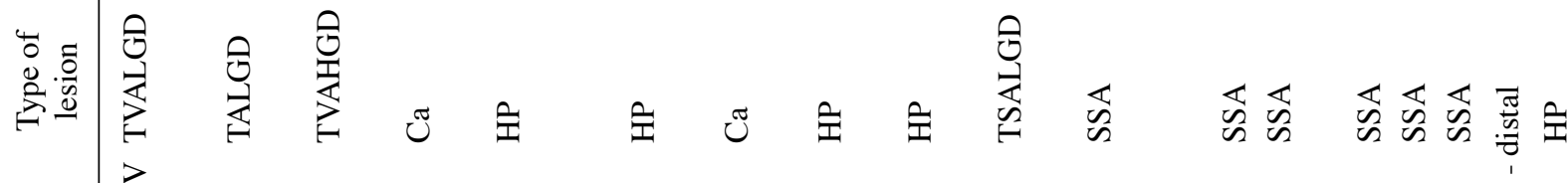

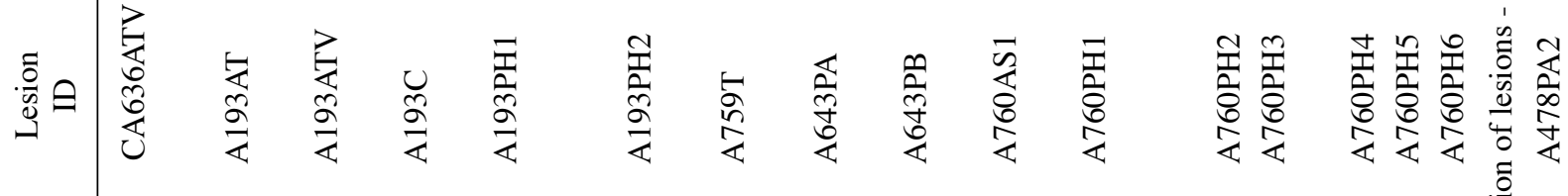

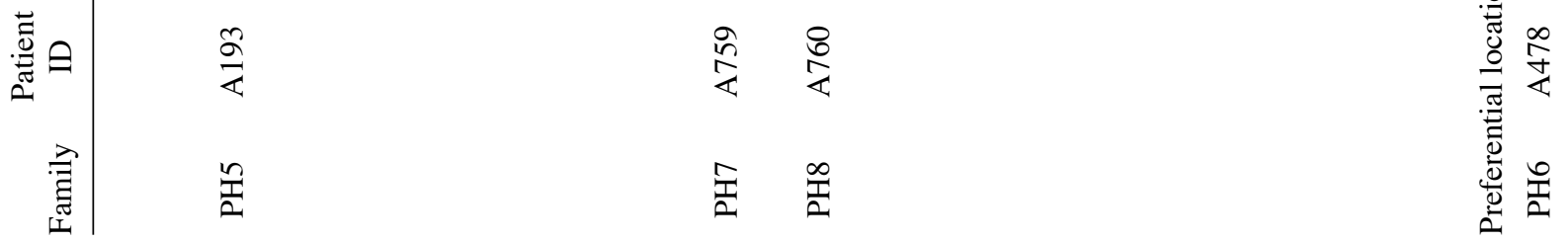




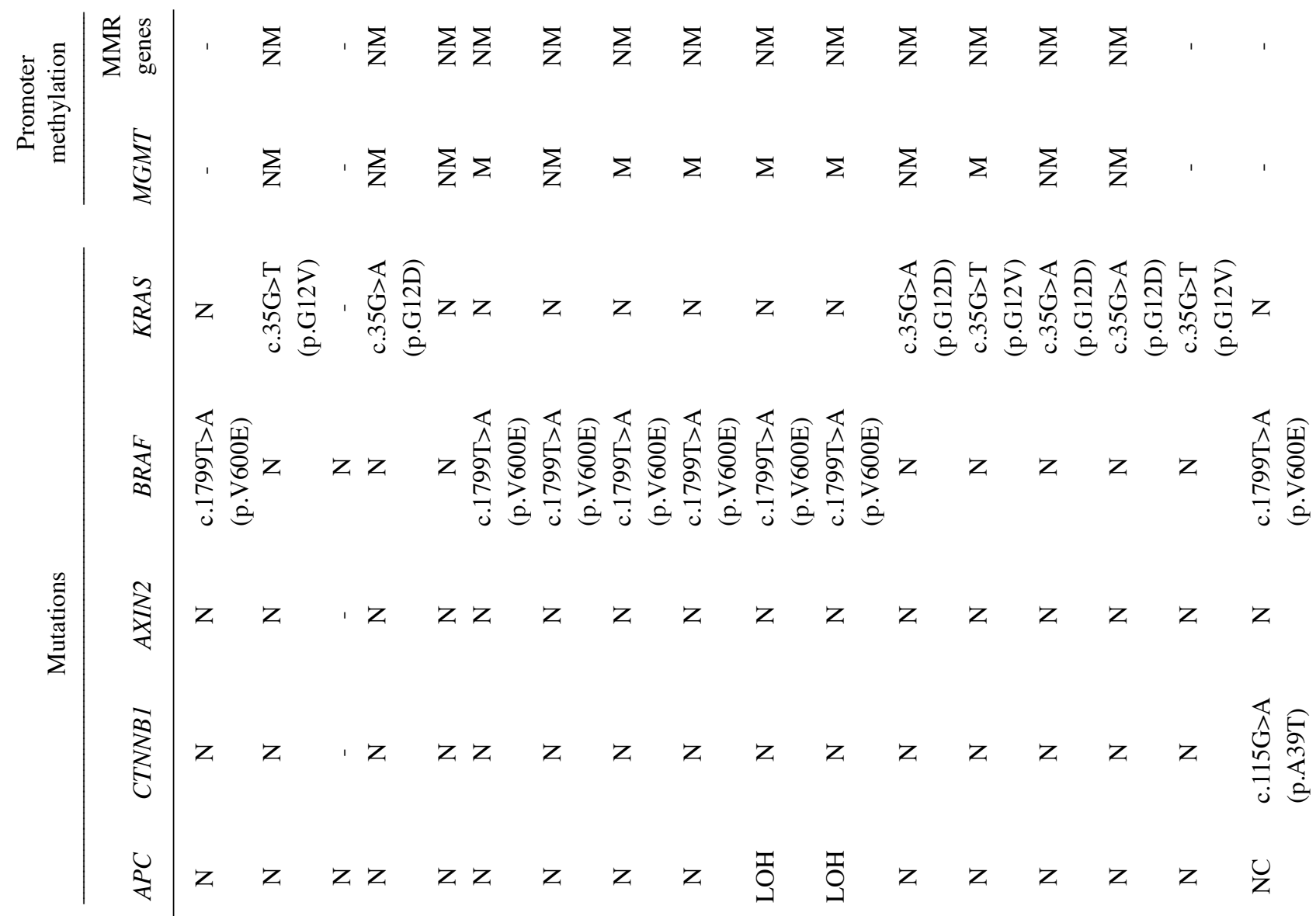

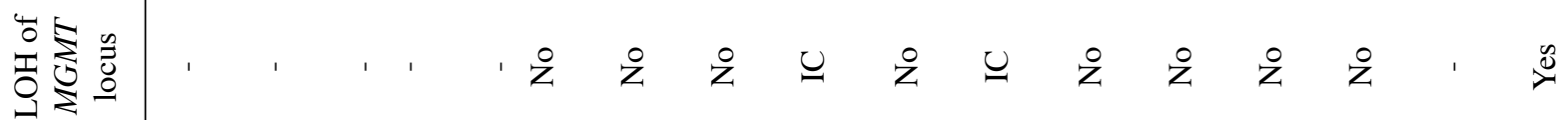

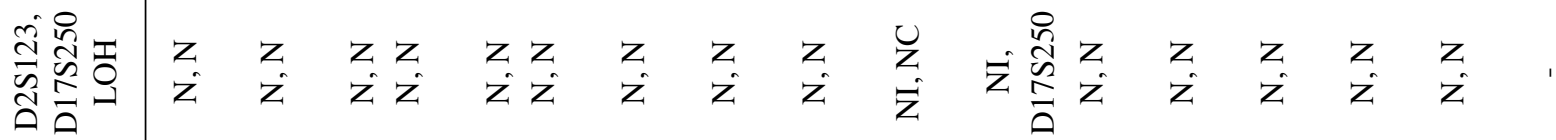

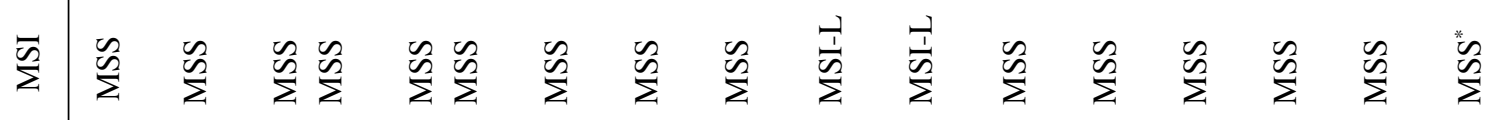

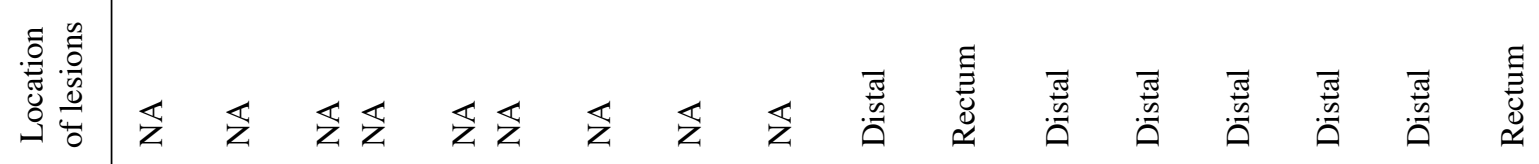

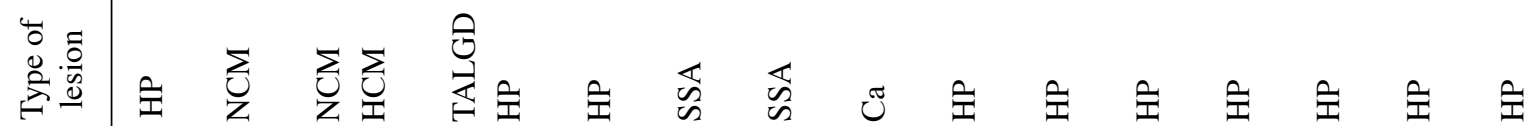

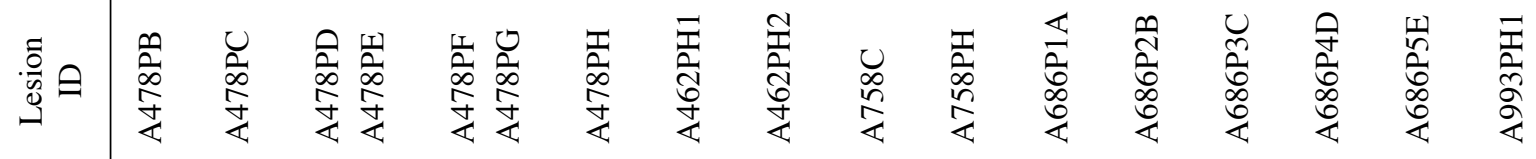

莺

$\stackrel{\infty}{\stackrel{\infty}{\gtrless}} \quad \stackrel{\infty}{\gtrless}$

ڤ̊

$\stackrel{\stackrel{ \pm}{\Xi}}{\stackrel{\Xi}{\Xi}}$

$\stackrel{2}{2}$ 


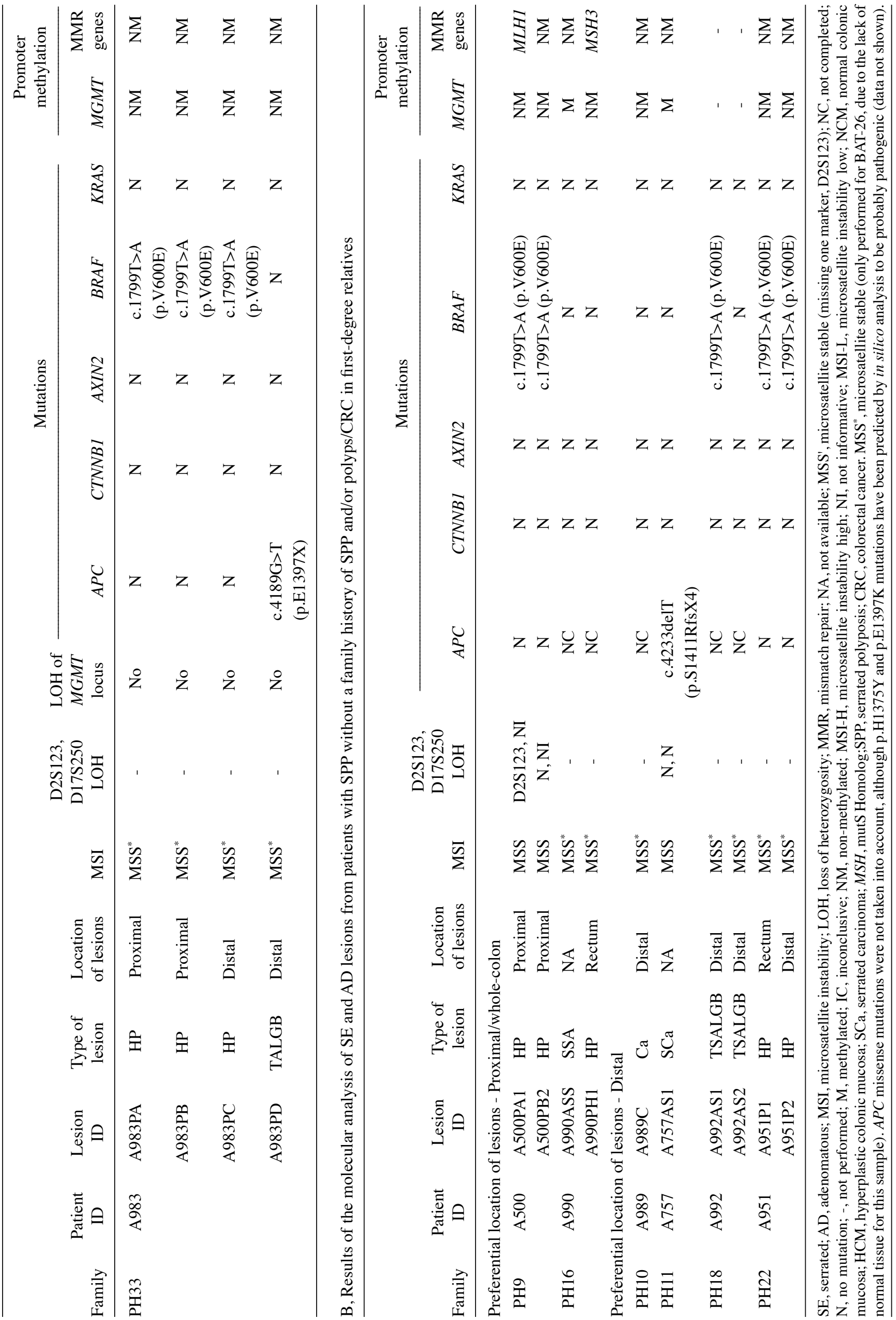


Table IV. Molecular characterization of lesions from patients with SPP-FHP/CRC, stratified by preferential location of the lesions in each patient.

\begin{tabular}{|c|c|c|c|}
\hline \multirow[b]{2}{*}{ Molecular characterization } & \multicolumn{2}{|c|}{ Preferential location of lesions } & \multirow[b]{2}{*}{ p-value } \\
\hline & Proximal/whole-colon & Distal colon & \\
\hline Total Wnt gene mutations & $14 / 26(54 \%)$ & $4 / 20(20 \%)$ & $\mathbf{0 . 0 2}{ }^{\mathrm{b}}$ \\
\hline Total RAS/RAF gene mutations & $12 / 30(40 \%)$ & $18 / 20(90 \%)$ & $3.7 \times 10^{-4 b}$ \\
\hline$B R A F$ gene mutations & $7 / 30(23 \%)$ & $12 / 20(60 \%)$ & $0.0089\left(\chi^{2}\right.$ test $)$ \\
\hline$K R A S$ gene mutations & $5 / 32(16 \%)$ & $6 / 20(30 \%)$ & NS \\
\hline $\mathrm{MSI}^{\mathrm{a}}$ & $15 / 26(58 \%)$ & $2 / 15(13 \%)$ & $0.0059^{b}$ \\
\hline MMR gene methylation and/or LOH of D2S123 & $17 / 18(94 \%)$ & $0 / 11$ & $3.0 \times 10^{-7 b}$ \\
\hline$M G M T$ gene methylation & $19 / 29(65 \%)$ & $7 / 17(41 \%)$ & NS \\
\hline LOH of $M G M T$ locus & $16 / 23(70 \%)$ & $1 / 14(7 \%)$ & $2.2 \times 10^{-4 b}$ \\
\hline \multicolumn{4}{|c|}{$\begin{array}{l}\text { 'Except for one lesion, microsatellite instability (MSI), either microsatellite instability-low (MSI-L) or microsatellite instability-high (MSI-H), was } \\
\text { detected only in dinucleotide microsatellite markers. 'Fisher's exact test (two-sided). SPP, serrated polyposis; CRC, colorectal cancer; SPP-FHP/CRC, } \\
\text { SPP associated with a family history of SPP and/or polyps/CRC (multiple or diagnosed at a young age) in first-degree relatives; MMR, mismatch } \\
\text { repair; LOH, loss of heterozygosity; MGMT, O-6-methylguanine-DNA methyltransferase. Statistically significant values are shown in bold. NS, non- } \\
\text { significant }(\mathrm{p}>0.05 \text { ). }\end{array}$} \\
\hline
\end{tabular}

both SE and AD lesions, compared with the lesions in patients with sporadic SPP, suggests the involvement of other pathways in the tumorigenic process associated with SPP-FHP/CRC, in addition to the serrated pathway of tumorigenesis.

Molecular alterations involved in tumor initiation distinguish between two forms of SPP-FHP/CRC: proximal/whole-colon and distal. Two forms of SPP-FHP/CRC appear to exist according to the preferential location of the lesions in the colon and rectum, proximal/whole-colon and distal, which differ with respect to the somatic events involved in tumor initiation. $\mathrm{LOH}$ and methylation of $M G M T$, MMR gene methylation and/or LOH of D2S123 and Wnt gene mutations appear to be the major somatic events that lead to tumor initiation in proximal/whole-colon SPP-FHP/CRC. By contrast, in distal SPP-FHP/CRC, KRAS or BRAF mutations were found in the majority of early lesions and thus seem to play a major role in tumor initiation.

We have previously shown that distinct Wnt gene mutations are selected in sporadic and hereditary CRC according to tumor location, i.e. proximal or distal colon $(33,42)$. We and others have also proposed that this finding is the result of the selection of a specific level of $\beta$-catenin signaling, optimal for tumor formation, which differs along the colorectum, thus contributing to differences in lesion distribution in specific types of CRC, such as Lynch syndrome $(42,43)$. Proving this, variable gradients in the number of stem cells and physiological Wnt activity have been demonstrated throughout the length of the intestinal tract (44). Thus, in a similar fashion, tumorigenic pathways may also differ between proximal and distal SPP-FHP/CRC.

MGMT and MMR alterations, followed by Wnt gene mutations, are involved in the initiation of proximal/wholecolon SPP-FHP/CRC. The exclusive detection of MMR gene methylation (mainly of MSH6) and/or LOH of D2S123 (flanking MSH6) in proximal/whole-colon SPP-FHP/CRC, in the majority of early lesions and in all histological types, appears to suggest that the MMR system plays an important role in the initiation of proximal/whole-colon SPP-FHP/CRC, which is in agreement with the high frequency of MSI (either MSI-L or MSI-H) in these lesions (58\%). Interestingly, MMR methylation and, consequently, MMR deficiency were not associated with $\mathrm{MLH1}$ methylation as has been previously observed in sporadic SE lesions located in the proximal colon (7), but rather with MSH6 or mutS homolog 3 (MSH3) methylation. Accordingly, a high frequency of LOH of the $\mathrm{MSH3}$ locus has been recently described in sporadic MSI-L $\mathrm{CRC}$, suggesting that the impairment of other MMR genes such as MSH3 or MSH6, as observed in the present study, are involved in an MSI-L pathway, instead of $M L H 1$, which is usually associated with the MSI-H serrated pathway (45). The detection of MSI almost exclusively in dinucleotide microsatellite markers is in agreement with this finding, since this type of MSI has been described to be a characteristic feature of MSI-L tumors (46). Interestingly, in the present study, MSI was detected more frequently at D2S123 followed by $\mathrm{D} 17 \mathrm{~S} 250$.

MGMT methylation and LOH of the MGMT locus were the most frequent alterations in proximal/whole-colon SPP-FHP/CRC, and MGMT methylation was detected in all HPs, commonly known as the precursor lesion (12). Therefore, we suggest that, similarly to MMR alterations, $\mathrm{LOH}$ and methylation of $M G M T$ may also be early events in SPP-FHP/CRC proximal/whole-colon tumorigenesis. Notably, among the 17 lesions informative for both MMR and MGMT alterations in this form of SPP-FHP/CRC, in 16 (94\%) both events were noted (Table IIIA). It is known that MGMT deficiency results in the inability to repair O6-methylguanine in the DNA, caused by genotoxic stress, which, once accumulated, 


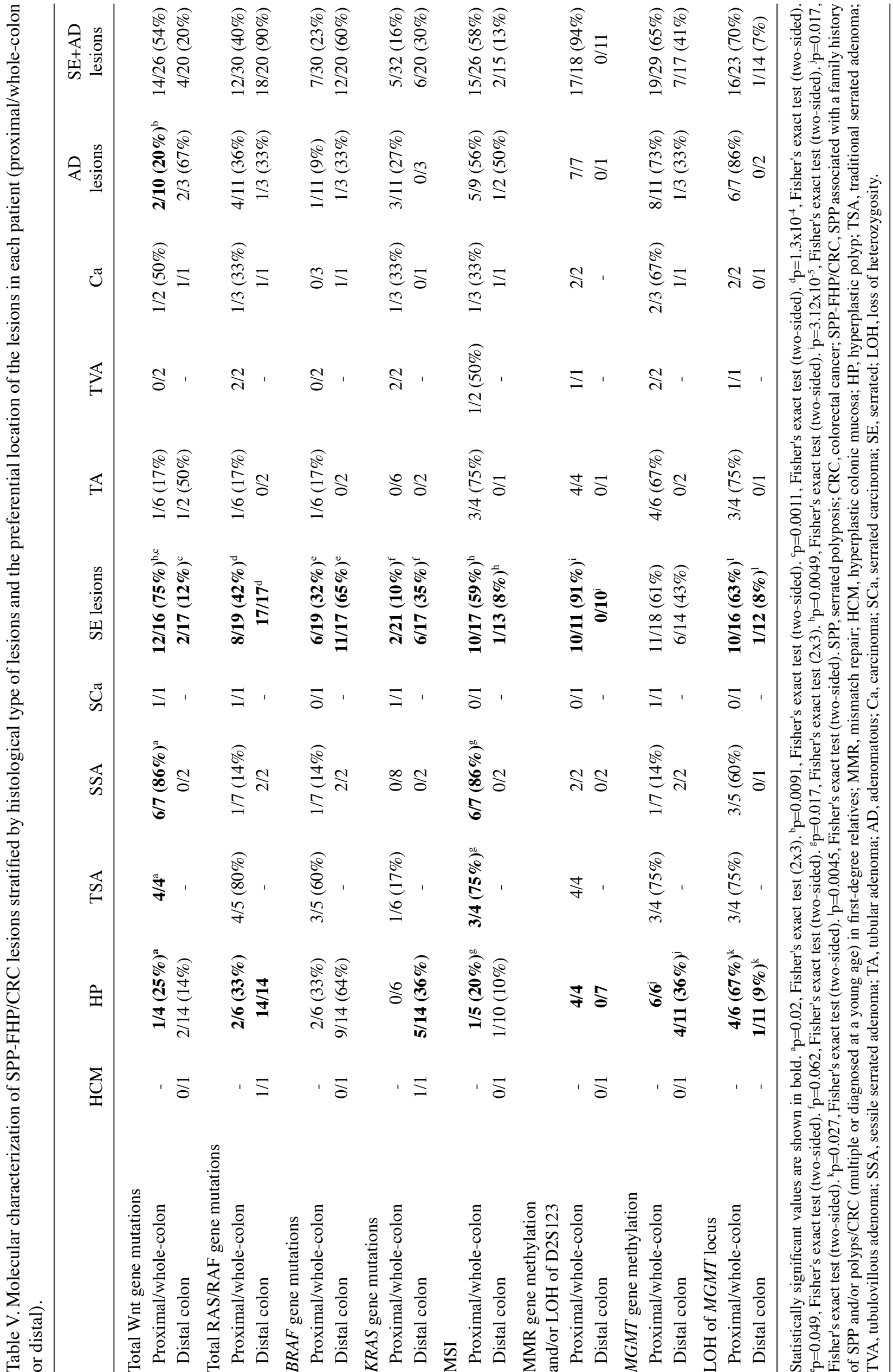


Preferential location: proximal/whole-colon
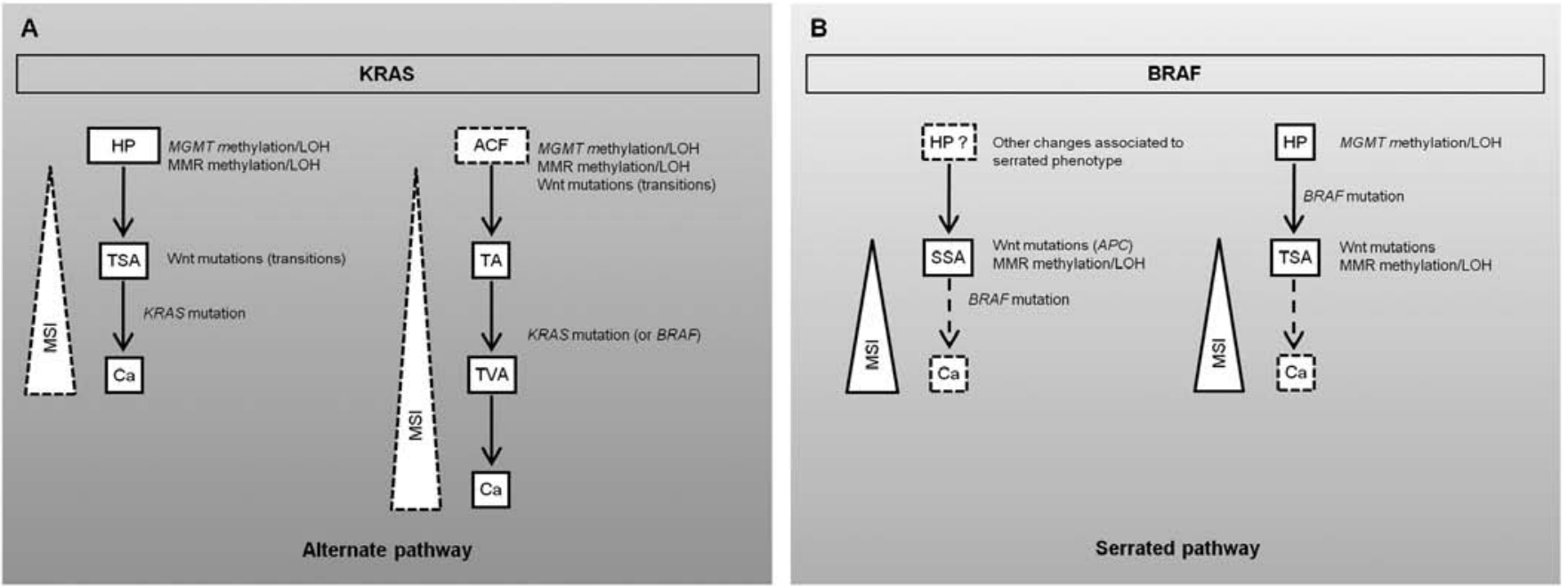

Preferential location: distal colon
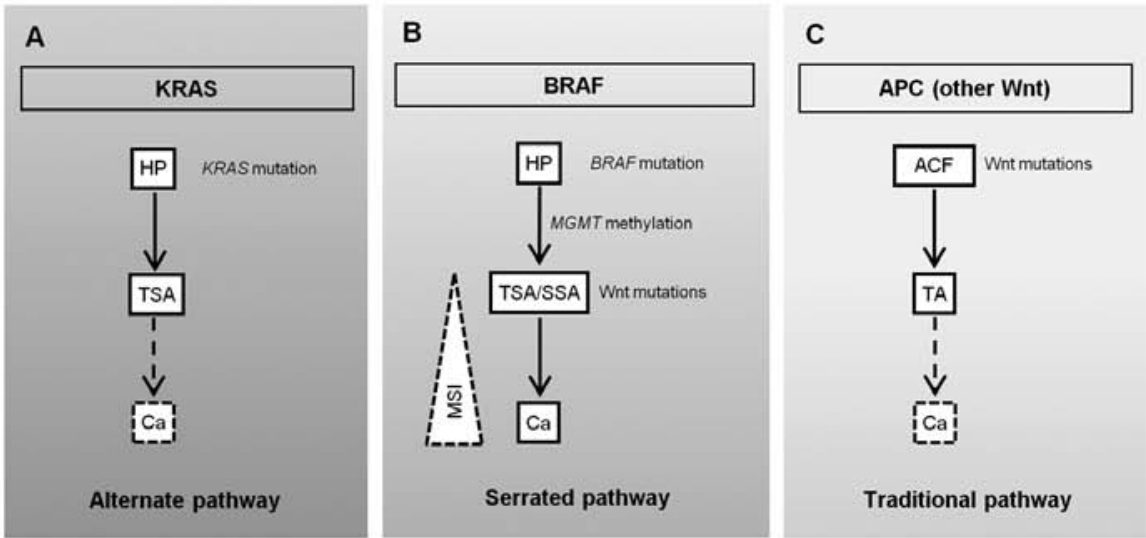

Figure 1. Proposed pathways for colorectal tumorigenesis in proximal/whole-colon (upper panel) and distal serrated polyposis (SPP) associated with a family history of SPP and/or polyps/colorectal cancer (SPP-FHP/CRC) (bottom panel). Both of these forms may follow a KRAS (alternate) or a BRAF (serrated) pathway, (A and B), respectively, in the upper and lower panels. In addition, in distal SPP, an adenomatous polyposis coli (APC) (traditional) pathway may also occur $[(\mathrm{C})$ in bottom panel]. Each lesion or molecular alteration in these proposed pathways is hypothesized based on the results obtained in the present study and we do not exclude that, in some cases, some of these molecular alterations may not occur, or even that other molecular alterations may also be found. The steps involving lesions that were not analyzed in this study and about which we have previously published information are represented by broken arrows. In some pathways a broken line was used to represent the increase in microsatellite instability (MSI) with tumor progression, to suggest a lower frequency in those cases. Ca, carcinoma; HP, hyperplastic polyp; MMR, mismatch repair; SSA, sessile serrated adenoma; TA, tubular adenoma; TSA, traditional serrated adenoma; TVA, tubulovillous adenoma.

leads to the translocation of the MutS $\alpha$ complex (MSH2 and MSH6) into the nucleus, thus increasing GT mismatch binding activity (47). This may lead to a selective pressure for molecular changes that impair MSH2 or MSH6 function such as promoter hypermethylation or $\mathrm{LOH}$, thus explaining the association between the latter and MGMT methylation in the same early SPP-FHP/CRC lesions. Thus, we suggest a primary role for MGMT methylation, O6-methylguanine errors and MMR alterations in tumor initiation of proximal/whole-colon SPP-FHP/CRC. We further suggest that this molecular signature may indicate that a germline defect in the mechanisms regulating the response to genotoxic stress underlies the genetic susceptibility in this form of SPP-FHP/CRC.

In the present study, the higher frequency of Wnt gene mutations in proximal SPP-FHP/CRC, particularly in SE lesions, when compared with the AD lesions, suggests that this pathway also plays an important role in this form of SPP-FHP/CRC, especially in the transition to SE adenoma since this frequency was significantly higher in TSA and SSA than in HP and HCM $\left(\mathrm{p}=8.4 \times 10^{-4}\right)$. In agreement, CTNNB1 or AXIN2 mutations, that are selected almost exclusively in proximal colorectal tumors with MSI (33), were detected in 4/14 (28\%) TSAs and SSAs from proximal/whole-colon SPP-FHP/CRC. Moreover, among $A P C$ nonsense and missense mutations, the majority $(7 / 8 ; 88 \%)$ were of the transition type which is a characteristic feature of cells presenting MMR defects (48-50).

The occurrence of LOH of D2S123 and/or D17S250 dinucleotide marker in the present study [17/48 (35\%) and 7/51 (14\%), respectively], has been previously described in Paneth cell metaplasia, a condition that is commonly observed in the small intestine and the proximal colon of elderly individuals $(51,52)$. Therefore, $M G M T$ deficiency may make these cells more exposed to genotoxic stress, thus leading to molecular changes in Wnt genes and consequently to commitment to Paneth cell 
lineage [to which Wnt gene mutations largely contribute (53)] and to Paneth cell metaplasia. Therefore, colonic mucosa with Paneth cell metaplasia may be one of the pre-neoplastic lesions in the development of proximal/whole-colon SPP-FHP/CRC.

$B R A F$ and KRAS mutations play different roles in proximal and distal SPP-FHP/CRC. Our finding that patients with proximal/whole-colon or distal SPP-FHP/CRC may carry, preferentially, either $K R A S$ or $B R A F$ mutations, supports previous observations suggesting that different forms of SPP exist, depending on whether lesions follow a KRAS or a BRAF pathway (22).

In addition, in the present study, we noted distinct roles for these mutations between proximal and distal SPP-FHP/ CRC. BRAF or KRAS mutations were detected in the majority of distal SPP-FHP/CRC lesions, mostly SE early lesions, thus underlining their importance in early stages, whereas in proximal/whole-colon SPP-FHP/CRC these mutations (mainly of $K R A S)$ appear to be more important in tumor progression (mostly detected in TSAs, TVAs and Cas). Accordingly, a KRAS or alternate pathway has been proposed to be involved in the transition from TSA or TVA to CRC in SPP (10). Indeed, in patients with proximal/whole-colon SPP-FHP/ CRC, KRAS mutations were found only in TSAs, TVAs or Cas (PH4, PH5 and PH7) which is in accordance with their association with the development of a villous architecture and hence with malignant transformation (10,54-56). Therefore, as TSAs and TVAs shared early somatic events with HPs and TAs, respectively, from the same patients, and based on the model of SPP tumorigenesis previously presented by Leggett and Whitehall (10), we propose that proximal/whole-colon SPP-FHP/CRC tumorigenesis may follow an alternate or KRAS pathway, where TVA and TSA may develop from TA and HP, respectively, finally leading to CRC, that may or may not present with MSI (Fig. 1A, upper panel). Alternatively, a serrated or BRAF pathway (families PH3 and PH8) where SSA or TSA will probably lead to MSI-H cancer carrying $B R A F$ mutations may also occur (Fig. 1B, upper panel). In this model, a deficient DNA repair pathway characterized by $M G M T$ and MMR gene methylation and/or LOH followed by Wnt gene mutations, appears to be predominant in proximal SPP-FHP/CRC (Fig. 1, upper panel).

In distal SPP-FHP/CRC, either KRAS (PH6 and PH14) or $B R A F$ (PH6, PH12, PH19 and PH33) mutations play a major role in tumor initiation, either through an alternate or a serrated pathway (Fig. 1A and B, bottom panel, respectively). Wnt gene mutations and MMR defects were detected in the only carcinoma presented by these patients and thus are likely involved in tumor progression. As PH6 and PH33 also presented TAs and did not present TVAs, we hypothesize that, in distal SPP-FHP/CRC, some AD lesions may also develop through a traditional pathway initiated by $A P C$ mutations (Fig. 1C, bottom panel).

CRC is more frequent in patients with proximal/whole-colon SPP-FHP/CRC with TSAs, TVAs and KRAS mutations. The association of KRAS mutations in TSA or TVA with the development of CRC in proximal/whole-colon SPP-FHP/CRC suggests a higher contribution of the alternate pathway in the development of CRC in patients with SPP-FHP/CRC. Supporting our hypothesis, $K R A S$ mutations have been previously described as more prevalent than $B R A F$ mutations in a series of SE carcinomas occurring in the sporadic context, mainly in those presenting adjacent serrated adenomas (51\%) (57). Moreover, in the same study, SE carcinomas were frequently MSS and presented a higher frequency of MGMT loss compared with traditional carcinomas, which is in agreement with our findings demonstrating that $M G M T$ deficiency plays a prominent role in SPP-FHP/CRC, mainly in the proximal colon.

The findings that KRAS and BRAF mutations promote serrated and hyperplastic features, despite being incapable of initiating colonic adenoma development by themselves $(58,59)$, may contribute to the apparent lower incidence of CRC in distal SPP-FHP/CRC, as according to the results of our present study, KRAS or BRAF mutations appear to be the initial molecular events in this form. However, additional studies involving more families are warranted.

In conclusion, SPP-FHP/CRC appears to be a distinct clinical and histological entity differing from sporadic SPP. However, we suggest that two forms of SPP-FHP/CRC appear to exist, proximal/whole-colon and distal, which differ mainly in the molecular alterations detected in early lesions. We further propose that a germline defect in the mechanisms regulating the response to genotoxic damage may underlie the genetic susceptibility in the former. In addition, our results suggest that CRC appears to develop more frequently in proximal/whole-colon SPP-FHP/CRC following an alternate KRAS pathway, thus underlining the importance of a complete clinical, histological and molecular characterization for CRC risk evaluation in further studies involving families with SPP. The results of these studies may be used to design appropriate guidelines for the clinical management of proximal and distal colonic presentations of SPP that assumes major relevance considering the increased risk of CRC and/or polyps in firstdegree relatives.

\section{Acknowledgements}

The authors thank all the patients who participated in this study, Dr Inês Francisco for the DNA extraction and Dr Branca Cavaco for the primers for the NRAS gene. This study was sponsored and financed by a grant from Núcleo Regional do Sul, Liga Portuguesa Contra o Cancro, Terry Fox (NRS/LPCC-Terry Fox), and Fundação para a Ciência e Tecnologia (FCT), POCI/ SAU-OBS/56921/2004.

\section{References}

1. Snover DC, Ahnen DJ, Burt RW and Odze RD: Serrated polyps of the colon and rectum and serrated polyposis. In: WHO Classification of Tumours of the Digestive System. Bosman FT, Carneiro F, Hruban RH and Theise ND (eds). IARC, Lyon, pp160-165, 2010

2. Kalady MF, Jarrar A, Leach B, LaGuardia L, O'Malley M, Eng C and Church JM: Defining phenotypes and cancer risk in hyperplastic polyposis syndrome. Dis Colon Rectum 54: 164-170, 2011.

3 . Rosty C, Parry S and Young JP: Serrated polyposis: an enigmatic model of colorectal cancer predisposition. Pathol Res Int 2011: 157073, 2011.

4. Snover DC, Jass JR, Fenoglio-Preiser C and Batts KP: Serrated polyps of the large intestine: a morphologic and molecular review of an evolving concept. Am J Clin Pathol 124: 380-391, 2005. 
5. Aust DE and Baretton GB; Members of the Working Group GI-Pathology of the German Society of Pathology: Serrated polyps of the colon and rectum (hyperplastic polyps, sessile serrated adenomas, traditional serrated adenomas, and mixed polyps)-proposal for diagnostic criteria. Virchows Arch 457: 291-297, 2010

6. Rosty C, Hewett DG, Brown IS, Leggett BA and Whitehall VL: Serrated polyps of the large intestine: current understanding of diagnosis, pathogenesis, and clinical management. J Gastroenterol 48: 287-302, 2013.

7. Young $\mathbf{J}$ and Jass JR: The case for a genetic predisposition to serrated neoplasia in the colorectum: hypothesis and review of the literature. Cancer Epidemiol Biomarkers Prev 15: 1778-1784, 2006.

8. Lindor NM: Hereditary colorectal cancer: MYH-associated polyposis and other newly identified disorders. Best Pract Res Clin Gastroenterol 23: 75-87, 2009.

9. Roberts A, Nancarrow D, Clendenning M, Buchanan DD, Jenkins MA, Duggan D, Taverna D, McKeone D, Walters R, Walsh MD, et al: Linkage to chromosome 2q32.2-q33.3 in familial serrated neoplasia (Jass syndrome). Fam Cancer 10 245-254, 2011.

10. Leggett $B$ and Whitehall V: Role of the serrated pathway in colorectal cancer pathogenesis. Gastroenterology 138 : 2088-2100, 2010

11. Jass JR, Iino H, Ruszkiewicz A, Painter D, Solomon MJ, Koorey DJ, Cohn D, Furlong KL, Walsh MD, Palazzo J, et al: Neoplastic progression occurs through mutator pathways in hyperplastic polyposis of the colorectum. Gut 47: 43-49, 2000.

12. Jass JR, Young J and Leggett BA: Hyperplastic polyps and DNA microsatellite unstable cancers of the colorectum. Histopathology 37: 295-301, 2000

13. Snover DC: Update on the serrated pathway to colorectal carcinoma. Hum Pathol 42: 1-10, 2011.

14. Chan AO, Issa JP, Morris JS, Hamilton SR and Rashid A: Concordant $\mathrm{CpG}$ island methylation in hyperplastic polyposis Am J Pathol 160: 529-536, 2002.

15. Kambara T, Simms LA, Whitehall VL, Spring KJ, Wynter CV, Walsh MD, Barker MA, Arnold S, McGivern A, Matsubara N, et al: BRAF mutation is associated with DNA methylation in serrated polyps and cancers of the colorectum. Gut 53: 1137-1144, 2004.

16. Weisenberger DJ, Siegmund KD, Campan M, Young J, Long TI, Faasse MA, Kang GH, Widschwendter M, Weener D, Buchanan D, et al: $\mathrm{CpG}$ island methylator phenotype underlies sporadic microsatellite instability and is tightly associated with BRAF mutation in colorectal cancer. Nat Genet 38: 787-793, 2006.

17. Chow E, Lipton L, Lynch E, D'Souza R, Aragona C, Hodgkin L, Brown G, Winship I, Barker M, Buchanan D, et al: Hyperplastic polyposis syndrome: phenotypic presentations and the role of MBD4 and MYH. Gastroenterology 131: 30-39, 2006.

18. Yeoman A, Young J, Arnold J, Jass J and Parry S: Hyperplastic polyposis in the New Zealand population: a condition associated with increased colorectal cancer risk and European ancestry. N Z Med J 120: U2827, 2007.

19. Boparai KS, Mathus-Vliegen EM, Koornstra JJ, Nagengast FM, van Leerdam M, van Noesel CJ, Houben M, Cats A, van Hest LP, Fockens $\mathrm{P}$ and Dekker E: Increased colorectal cancer risk during follow-up in patients with hyperplastic polyposis syndrome: a multicentre cohort study. Gut 59: 1094-1100, 2010.

20. Minoo P, Baker K, Goswami R, Chong G, Foulkes WD, Ruszkiewicz AR, Barker M, Buchanan D, Young J and Jass JR: Extensive DNA methylation in normal colorectal mucosa in hyperplastic polyposis. Gut 55: 1467-1474, 2006.

21. Wynter CV, Walsh MD, Higuchi T, Leggett BA, Young J and Jass JR: Methylation patterns define two types of hyperplastic polyp associated with colorectal cancer. Gut 53: 573-580, 2004.

22. Carvajal-Carmona LG, Howarth KM, Lockett M, PolancoEcheverry GM, Volikos E, Gorman M, Barclay E, Martin L, Jones AM, Saunders B, et al: Molecular classification and genetic pathways in hyperplastic polyposis syndrome. J Pathol 212 378-385, 2007.

23. Guarinos C, Sánchez-Fortún C, Rodríguez-Soler M, Alenda C, Payá A and Jover R: Serrated polyposis syndrome: molecular, pathological and clinical aspects. World J Gastroenterol 18: 2452-2461, 2012

24. Boparai KS, Reitsma JB, Lemmens V, van Os TA, MathusVliegen EM, Koornstra JJ, Nagengast FM, van Hest LP, Keller JJ and Dekker E: Increased colorectal cancer risk in first-degree relatives of patients with hyperplastic polyposis syndrome. Gut 59: 1222-1225, 2010
25. Win AK, Walters RJ, Buchanan DD, Jenkins MA, Sweet K, Frankel WL, de la Chapelle A, McKeone DM, Walsh MD, Clendenning M, et al: Cancer risks for relatives of patients with serrated polyposis. Am J Gastroenterol 107: 770-778, 2012

26. Caetano AC, Ferreira H, Soares J, Ferreira A, Gonçalves R and Rolanda C: Phenotypic characterization and familial risk in hyperplastic polyposis syndrome. Scand J Gastroenterol 48: $1166-1172,2013$

27. Hazewinkel Y, Koornstra JJ, Boparai KS, van Os TA, Tytgat KM, van Eeden S, Fockens P and Dekker E: Yield of screening colonoscopy in first-degree relatives of patients with serrated polyposis syndrome. J Clin Gastroenterol, 2014.

28. Jasperson KW, Kanth P, Kirchhoff AC, Huismann D, Gammon A, Kohlmann W, Burt RW and Samadder NJ: Serrated polyposis: colonic phenotype, extracolonic features, and familial risk in a large cohort. Dis Colon Rectum 56: 1211-1216, 2013.

29. Lanspa SJ, Ahnen DJ and Lynch HT: Serrated polyposis: the last (or only the latest?) frontier of familial polyposis? Am J Gastroenterol 107: 779-781, 2012.

30. Albuquerque C, Breukel C, van der Luijt R, Fidalgo P, Lage P, Slors FJ, Leitão CN, Fodde R and Smits R: The 'just-right' signaling model: APC somatic mutations are selected based on a specific level of activation of the beta-catenin signaling cascade. Hum Mol Genet 11: 1549-1560, 2002.

31. Miller SA, Dykes DD and Polesky HF: A simple salting out procedure for extracting DNA from human nucleated cells. Nucleic Acids Res 16: 1215, 1988.

32. Francisco I, Albuquerque C, Lage P, Belo H, Vitoriano I, Filipe B, Claro I, Ferreira S, Rodrigues P, Chaves P, et al: Familial colorectal cancer type $\mathrm{X}$ syndrome: two distinct molecular entities? Fam Cancer 10: 623-631, 2011.

33. Albuquerque C, Baltazar C, Filipe B, Penha F, Pereira T, Smits R, Cravo M, Lage P, Fidalgo P, Claro I, et al: Colorectal cancers show distinct mutation spectra in members of the canonical WNT signaling pathway according to their anatomical location and type of genetic instability. Genes Chromosomes Cancer 49: 746-759, 2010

34. Liu W, Dong X, Mai M, Seelan RS, Taniguchi K, Krishnadath KK, Halling KC, Cunningham JM, Boardman LA, Qian C, et al: Mutations in AXIN2 cause colorectal cancer with defective mismatch repair by activating beta-catenin/TCF signalling. Nat Genet 26:146-147, 2000 .

35. Davies H, Bignell GR, Cox C, Stephens P, Edkins S, Clegg S, Teague J, Woffendin H, Garnett MJ, Bottomley W,et al: Mutations of the BRAF gene in human cancer. Nature 417: 949-954, 2002.

36. Boland CR, Thibodeau SN, Hamilton SR, Sidransky D, Eshleman JR, Burt RW, Meltzer SJ, Rodriguez-Bigas MA, Fodde R, Ranzani GN and Srivastava S: A National Cancer Institute Workshop on Microsatellite Instability for cancer detection and familial predisposition: development of international criteria for the determination of microsatellite instability in colorectal cancer. Cancer Res 58:5248-5257, 1998.

37. Umar A: Lynch syndrome (HNPCC) and microsatellite instability. Dis Markers 20:179-180, 2004.

38. Nygren AO, Ameziane N, Duarte HM, Vijzelaar RN, Waisfisz Q, Hess CJ, Schouten JP and Errami A: Methylation-specific MLPA (MS-MLPA): simultaneous detection of $\mathrm{CpG}$ methylation and copy number changes of up to 40 sequences. Nucleic Acids Res 33: e128, 2005

39. Gylling A, Ridanpää M, Vierimaa O, Aittomäki K, Avela K, Kääriäinen H, Laivuori H, Pöyhönen M, Sallinen SL, WallgrenPettersson C, et al: Large genomic rearrangements and germline epimutations in Lynch syndrome. Int J Cancer 124: 2333-2340, 2009.

40. Yamada A, Minamiguchi S, Sakai Y, Horimatsu T, Muto M, Chiba T, Boland CR and Goel A: Colorectal advanced neoplasms occur through dual carcinogenesis pathways in individuals with coexisting serrated polyps. PLoS One 9: e98059, 2014.

41. Filipe B, Baltazar C, Albuquerque C, Fragoso S, Lage P, Vitoriano I, Mão de Ferro S, Claro I, Rodrigues P, Fidalgo P, et al. APC or MUTYH mutations account for the majority of clinically wellcharacterized families with FAP and AFAP phenotype and patients with more than 30 adenomas. Clin Genet 76:242-255, 2009.

42. Albuquerque C, Bakker ER, van Veelen W and Smits R: Colorectal cancers choosing sides. Biochim Biophys Acta 1816: 219-231, 2011.

43. Christie M, Jorissen RN, Mouradov D, Sakthianandeswaren A, Li S, Day F, Tsui C, Lipton L, Desai J, Jones IT, et al: Different APC genotypes in proximal and distal sporadic colorectal cancers suggest distinct WNT/ $\beta$-catenin signalling thresholds for tumourigenesis. Oncogene 32: 4675-4682, 2013. 
44. Leedham SJ, Rodenas-Cuadrado P, Howarth K, Lewis A Mallappa S, Segditsas S, Davis H, Jeffery R, Rodriguez-Justo M, Keshav S, et al: A basal gradient of Wnt and stem-cell number influences regional tumour distribution in human and mouse intestinal tracts. Gut 62: 83-93, 2013.

45. Plaschke J, Preussler M, Ziegler A and Schackert HK: Aberrant protein expression and frequent allelic loss of MSH3 in colorectal cancer with low-level microsatellite instability. Int J Colorectal Dis 27: 911-919, 2012.

46. Hatch SB, Lightfoot HM Jr, Garwacki CP, Moore DT, Calvo BF, Woosley JT, Sciarrotta J, Funkhouser WK and Farber RA: Microsatellite instability testing in colorectal carcinoma: choice of markers affects sensitivity of detection of mismatch repair-deficient tumors. Clin Cancer Res 11: 2180-2187, 2005

47. Christmann M and Kaina B: Nuclear translocation of mismatch repair proteins $\mathrm{MSH} 2$ and MSH6 as a response of cells to alkylating agents. J Biol Chem 275: 36256-36262, 2000.

48. Sohn KJ, Choi M, Song J, Chan S, Medline A, Gallinger S and Kim YI: Msh2 deficiency enhances somatic Apc and p53 mutations in $\mathrm{Apc}^{+/-} \mathrm{Msh}^{-/-}$mice. Carcinogenesis 24: 217-224, 2003.

49. Oliveira C, Westra JL, Arango D, Ollikainen M, Domingo E, Ferreira A, Velho S, Niessen R, Lagerstedt K, Alhopuro P, et al: Distinct patterns of KRAS mutations in colorectal carcinomas according to germline mismatch repair defects and hMLH1 methylation status. Hum Mol Genet 13: 2303-2311, 2004.

50. Mark SC, Sandercock LE, Luchman HA, Baross A, Edelmann W and Jirik FR: Elevated mutant frequencies and predominance of G:C to A:T transition mutations in Msh6(-/-) small intestinal epithelium. Oncogene 21: 7126-7130, 2002.

51. Wada R, Yamaguchi T and Tadokoro K: Colonic Paneth cell metaplasia is pre-neoplastic condition of colonic cancer or not? J Carcinog 4: 5, 2005

52. Wada R: Proposal of a new hypothesis on the development of colorectal epithelial neoplasia:nonspecific inflammation - colorectal Paneth cell metaplasia - colorectal epithelial neoplasia. Digestion 79 (Suppl 1): 9-12, 2009.
53. Andreu P, Peignon G, Slomianny C, Taketo MM, Colnot S, Robine S, Lamarque D, Laurent-Puig P, Perret C and Romagnolo B: A genetic study of the role of the Wnt/betacatenin signalling in Paneth cell differentiation. Dev Biol 324: 288-296, 2008

54. Sada M, Mitomi H, Igarashi M, Katsumata T, Saigenji K and Okayasu I: Cell kinetics, p53 and bcl-2 expression, and c-Ki-ras mutations in flat-elevated tubulovillous adenomas and adenocarcinomas of the colorectum: comparison with polypoid lesions. Scand J Gastroenterol 34: 798-807, 1999.

55. Maltzman T, Knoll K, Martinez ME, Byers T, Stevens BR, Marshall JR, Reid ME, Einspahr J, Hart N, Bhattacharyya AK, et al: Ki-ras proto-oncogene mutations in sporadic colorectal adenomas: relationship to histologic and clinical characteristics. Gastroenterology 121: 302-309, 2001.

56. Jass JR, Baker K, Zlobec I, Higuchi T, Barker M, Buchanan D and Young J: Advanced colorectal polyps with the molecular and morphological features of serrated polyps and adenomas: concept of a 'fusion' pathway to colorectal cancer. Histopathology 49: 121-131, 2006.

57. García-Solano J, Conesa-Zamora P, Carbonell P, Trujillo-Santos J, Torres-Moreno D D, Pagán-Gómez I, Rodríguez-Braun E and Pérez-Guillermo M: Colorectal serrated adenocarcinoma shows a different profile of oncogene mutations, MSI status and DNA repair protein expression compared to conventional and sporadic MSI-H carcinomas. Int J Cancer 131: 1790-1799, 2012.

58. Feng Y, Bommer GT, Zhao J, Green M, Sands E, Zhai Y, Brown K, Burberry A, Cho KR and Fearon ER: Mutant KRAS promotes hyperplasia and alters differentiation in the colon epithelium but does not expand the presumptive stem cell pool. Gastroenterology 141: 1003-1013.e1-10, 2011.

59. Carragher LA, Snell KR, Giblett SM, Aldridge VS, Patel B, Cook SJ, Winton DJ, Marais R and Pritchard CA: V600EBraf induces gastrointestinal crypt senescence and promotes tumour progression through enhanced $\mathrm{CpG}$ methylation of p16INK4a. EMBO Mol Med 2: 458-471, 2010. 